Public Health NutritionVolume 20, Issue 5, 1 April 2017, Pages 948-949

\title{
An update on the status of front-of-package labelling regulations in Latin America(Letter)
}

- Robles-Valcarcel, P.Email Author

- View Correspondence (jump link)

- School of Nutrition and Dietetics, Universidad Peruana de Ciencias

Aplicadas, Av. Alameda San Marcos cuadra 2 s/n, Chorrillos, Lima, Peru

Abstract_View references (17)

[No abstract available]

- ISSN: 13689800

- CODEN: PHNUF

- Source Type: Journal

- Original language: English

- DOI: $10.1017 / \mathrm{S} 1368980016003359$

- Document Type: Letter

- Publisher: Cambridge University Press 